\title{
Nota sobre la mismidad en la filosofía griega
}

\section{Note about selfhood in Greek philosophy}

\author{
ALEJANDRO ROJAS JIMÉNEZ \\ Universidad de Málaga
}

Recibido: 08-02-2007 Aprobado definitivamente: 18-05-2007

RESUMEN

Breve análisis sobre la mismidad en el mundo griego clásico como planteamiento para presentar la filosofía aristotélica.

\author{
PALABRAS CLAVES \\ MOVIMIENTO CIRCULAR, ENÉRGEIA, MISMIDAD, IDENTIDAD
}

\begin{abstract}
This paper is a brief analysis on the selfhood in the classic Greek world in order to present the Aristotelian philosophy.

KEYWORDS

CIRCULAR MOVEMENT, ENÉRGEIA, SELFHOOD, IDENTITY
\end{abstract}

\section{INTRODUCCIÓN}

Decimos que la filosofía se inicia con la sentencia «todo es agua». Con esta afirmación no señalamos simplemente un mero comienzo histórico. Cuando decimos que con dicha sentencia se inicia la filosofía decimos que en dicha sentencia se encuentra ya aquello que hace que un pensamiento sea filosófico, algo que, por supuesto, debe permanecer en el pensamiento filosófico posterior en la medida en que aún digamos de éste que es un pensar filosofante. $O$ dicho 
de otra manera, lo que hace que la proposición «todo es agua» sea una proposición filosófica, debe seguir actuando en el pensamiento filosófico posterior en la medida en que decimos que, como el de Tales, se trata de un pensamiento filosófico.

Pues bien, si nos fijamos en la sentencia «todo es agua» lo que vemos en ella es una relación de identidad. Lo que hace Tales es establecer la unidad entre ente y ser como una relación de identidad para responder a la pregunta por el arkhé. Lo que hace que la sentencia «todo es agua» sea una sentencia filosófica es que en ella se establece una unidad formulada como identidad para responder a la pregunta por el ser del ente.

Poco decimos si nos limitamos a indicar simplemente que se trata de una respuesta a la pregunta por el arkhé, es preciso además hacer ver que precisamente por tratarse de una pregunta por el arkhé lo que se hace es establecer una unidad. Y ello porque la búsqueda del ser del ente sólo puede emprenderse desde el descubrimiento de la unidad: todo pensamiento sobre el ser del ente consiste en un pensamiento sobre la unidad. Si bien, por supuesto, la unidad no tiene porqué pensarse sólo como identidad. Otras formas posibles son, por ejemplo, la universalidad y la analogía. ${ }^{1}$ En el último de los jonios disponemos de un claro ejemplo para poder observar cómo la relación de unidad no tiene porqué ser entendida como una relación de identidad. Para Heráclito lo que se da es una relación de mismidad: aunque todas las cosas son uno, ${ }^{2}$ dicha unidad respeta la oposición. La ley fundamental que gobierna el universo es la mismidad entre opuestos. Ser lo mismo no es ser idénticos. El modo como Heráclito piensa la unidad no anula la diferencia. Y por ello la imagen a la que recurre será la del fuego chispeante y siempre vivo, ${ }^{3}$ pues aún siendo el fuego siempre fuego (lo mismo) nunca es idéntico (chispeante y siempre vivo). Claro que haríamos mal en no señalar que es justamente en este sentido al que apuntan, aunque sin llegar a alcanzarlo, el agua en Tales, el aire en Anaxímenes y el infinito en Anaximandro.

Pensar la relación entre ente y ser como identidad ha sido una constante en la historia de la filosofía. La encontramos en el «todo es voluntad de poder»o en el todo es pensamiento y extensión como atributos de una única sustancia. Hasta tal punto es habitual en la historia de la filosofía formular la respuesta por el ser desde una relación de identidad, que un filósofo como Heidegger se verá así mismo como inaugurador de otro comienzo precisamente por pensar la diferencia en lugar de la identidad, esto es, la relación de mismidad entre pensar

1 Cfr., Juan García, «¿Siempre lo mismo, o algo nuevo?», Concepciones y narrativas del yo, Thémata, №22, 1999.

2 DK 22 B 50.

3 DK 22 B 30. 
y ser sin entenderla como una relación de identidad. Si bien creo que deberíamos considerar la rotunda afirmación heideggeriana con reticencias, lo cierto es que a partir de Heidegger, y especialmente de su Identität und Differenz se abre una fructífera línea filosofante que aún llega a nuestros días y que conocemos como los filósofos de la diferencia. ${ }^{4}$

Aunque ya hemos visto que no hay que ir muy lejos para observar un filósofo que no entienda la unidad como identidad. Y Heráclito habló de mismidad en lugar de identidad porque se había percatado de la imposibilidad de la identidad en el mundo sensible. Había visto que en la naturaleza nada permanece idéntico a sí mismo, que todo está en constante cambio. ${ }^{5}$ Parménides será aún más radical que Heráclito al considerar que en el mundo sensible ni siquiera la mismidad puede lograrse. Para el eleata no ya sólo nada permanece idéntico así mismo, sino que ni siquiera nada permanece lo mismo siempre frente a lo que Heráclito nos enseñaba sobre la lucha eterna de los contrarios regida por la ley universal del lógos.

El hallazgo especulativo que mueve al filosofar parmenídeo es precisamente haber descubierto un modo de ser que permanece lo mismo siempre en oposición al modo de ser de lo sensible. ${ }^{6}$

Lo que ha encontrado Parménides es, insisto, un modo de ser que permanece lo mismo siempre: lo pensado. Claro que este peculiar modo de ser de lo pensado no podía ser explicado desde la primacía del pensar (un rasgo típicamente moderno), sino que debía ser explciado a partir del qué pensado. Un griego no podrá decir que la mismidad de lo pensado se debe a la particular forma de pensar, para ellos si lo pensado permanecía lo mismo sólo podía serlo porque el qué pensado permanecía lo mismo. Por ello Parménides se verá empujado a afirmar la realidad de un Ser redondo ${ }^{7}$ que permanece lo mismo siempre, pues, en lo redondo no hay comienzo ni final. ${ }^{8}$

Lo pensado no sería pues el ser sensible al que vemos cambiante y contingente, sino una realidad que permanece siempre lo mismo. Platón dará el paso definitivo en esta línea al referirse a un topos noetós, en la medida en que con él la afirmación de que pensar no se refiere al mundo sensible cobra una formulación magistral que supera la tosca formulación del Ser Redondo y Uno. Claro

4 Cfr., Juan García, Después de Husserl. Estudios sobre la filosofía del siglo XX, Libros En Red, Buenos Aires, 2006.

5 Dk 22 B 12, 49a y 91.

6 En oposición a este peculiar modo de ser, el mundo sensible pasará a ser considerado como no-ser.

7 «Aber da eine letzte Grenze vorhanden, so ist es vollendet von (und nach) allen Seiten, einer wohlgerundeten Kugel Masse vergleichbar, von der Mitte her überall gleichgewichtig» DK 28 B 8,40.

8 Cfr., DK 22 B 103. 
que se mantiene en lo esencial del pensamiento parmenídeo en la medida en que Platón no hace otra cosa que localizar ónticamente la permanencia de lo mismo siempre. Saumells explicaba esto que decimos muy bienen en sus fundamentos de matemática y física: «los griegos habían atribuido a las matemáticas el carácter de una especie de sabiduría ultraterrena; una ciencia de la razón pura cuyo objetos eran entes inmutables, eternos, pertenecientes a un reino ideal situado fuera de nuestro mundo sensible, móvil, cambiante. El estudio de los números, de las relaciones espaciales, equivaldría, en la matemática de la antigüedad clásica, a una toma de contacto del espíritu con una cosa permanente, estable, esencialmente distinta, por tanto, de los objetos perecederos, mudables, que nacen y desaparecen en el escenario de la naturaleza sensible (...) Así, se creerá, en general, que la matemática debe la perfección de sus razonamientos, a la inmutabilidad de su objeto propio. Si quieres huir de la inquietud del mundo sensible -dirá el griegoejercita tu mente en el conocimiento de objetos estables».9

Claro que recurrir a un mundo ideal alternativo sólo tiene sentido ante la necesidad de explicar la mismidad de lo pensado desde la consideración de que a nivel sensible no puede lograrse dicha mismidad.

Pues bien, esto es lo que Aristóteles no concederá. El Estagirita ha descubierto que si lo pensado permanece siempre lo mismo es porque, precisamente, la permanencia de lo mismo sempre se da en el mundo sensible a pesar del cambio. Si bien no ya una mismidad formulada como armonía de contrarios, sino como una genial teoría del movimiento que por un lado nos dirige a un primer motor agente del movimiento que consigue que se de lo mismo siempre a pesar del cambio, mientras que, por otro lado, nos dirige al principio de causalidad final en tanto que el ordenamiento para dicho mantenimiento de lo mismo siempre a pesar del cambio obedece a la pretensión de actualidad como fin de toda sustancia.

\section{La Metafísica y la Física aRIstotélica}

Aristóteles continúa a Platón y Parménides en el descubrimiento de que lo pensado permanece siempre lo mismo, pero dará un alcance propio a este hallazgo mediante la noción de enérgeia. Lo que Aristóteles ha descubierto es que la actividad del pensar consiste precisamente en captar en un solo acto lo conocido, praxis teleia. ${ }^{10}$ La pregunta a cómo es posible que «lo pensado»

9 Saumells, Fundamentos de matemática y de física, Rialp, Madrid, 1965, p 92.

10 «Acción es aquella en la que se da el fin. Por ejemplo, uno ve y al mismo tiempo ha visto, piensa y ha pensado, entiende y ha entendido, pero no aprende y ha aprendido ni se cura y se ha curado» Metaph. IX, 6 1048b 23. 
permanezca lo mismo siempre (en acto) cuando el qué pensado cambia, es respondido por Aristóteles encontrando «lo mismo siempre» a nivel sensible a pensar del cambio: se trataba sencillamente de encontrar en el mundo sensible una estructura cíclica. ${ }^{11}$ Lo que ha visto Aristóteles es que si es posible que lo pensado permanezca lo mismo siempre es porque la naturaleza posee una estructura circular. ${ }^{12}$ Así, si podemos pensar por ejemplo el verano es porque se repite cíclicamente.

Claro que, habría que añadir, esta forma circular no se entendería sin una finalidad (causa causarum). Quiero decir, ¿porqué sabemos que algo es una semilla de un manzano? Porque está ordenada a dar manzanas. Su forma esta sujeta a su finalidad. ¿Por qué es de tal forma un hacha? Porque siendo de esa forma puede cortar árboles. La forma en el pensamiento aristotélico está subordinada a la finalidad. Siendo así que no deberíamos mantener que veamos porque tenemos ojos, sino que estamos organizados para ver porque ver esta al servicio de nuestra finalidad, que no hablamos porque tengamos boca, sino que porque somos capaces de hablar tenemos boca para ello. ${ }^{13}$

Ahora bien, la subordinación de la forma al fin va más allá de lo que hemos dicho. Ya que, siendo la finalidad opuesta a toda materialidad, la subordinación de la forma al fin significa que todo llegar a ser está subordinado a un intento de vencer la materia (paso de la potencia al acto). Claro que, por otro lado, a nivel sensible es imposible, pues a nivel sensible lo que hay es hilemorfísmo. La finalidad trasciende el Universo. Ahora bien, si podemos pensar lo sensible es porque de alguna manera se consigue vencer la materia.

Hay que insistir que la subordinación de la forma al fin revela una estructura cíclica. Si podemos conocer la semilla del manzano (captar su forma) es porque su finalidad, dar manzanas, se repite cíclicamente en el caer manzana y crecer manzanos de ellas. Por supuesto que no podemos afirmar que la finalidad de la semilla queda cumplida cuando la semilla se ha convertido en un manzano

11 «Por eso, lo que comúnmente se dice se sigue de lo anterior, pues se dice que los asuntos humanos son un círculo, y que hay un círculo en todas las otras cosas que tienen un movimiento natural y están sujetas a generación y destrucción. Y esto se dice porque todas estas cosas son juzgadas por el tiempo, y porque tienen un fin y un comienzo como si fuera un ciclo, pues se piensa que el tiempo mismo es un círculo; y se piensa así porque el tiempo es la medida de tal desplazamiento y él mismo es medido por este desplazamiento» Phys, 223b 25-30.

12 Empédocles también la había visto: «Puesto que el Uno aprendió a nacer de lo múltiple / y luego al dividirse el Uno se va realizando en lo múltiple, / así nacen las cosas y no tienen una vida estable, / pero como estos cambios mutuos no cesan jamás, / son siempre inmóviles en su ciclo» DK B 17, 9-13.

13 «Los animales, en efecto, no ven para tener vista, sino que tienen vista para ver, y de igual modo se tiene el arte de construir para construir, y el de especular para especular» Metaph. IX, 8 1050a 10. 
capaz de dar manzanas, pero en la medida en que esta estructura cíclica permite su pensabilidad, en la presencia actual (el manzano pensado) tiene su término la operación de llegar a ser en acto (paso de la potencia al acto). ${ }^{14}$

Con esta breve exposición vemos que de lo que se trata es de responder a dos preguntas vinculadas entre sí: la primera es ¿por qué puede ser pensada la naturaleza? Y la respuesta es que es posible porque se da la permanencia de lo mismo siempre a pesar del cambio. La segunda pregunta es ¿por qué está ordenada la naturaleza cíclicamente? Debido a la pretensión de actualidad de toda sustancia.

En el fondo, la clave de todo este sistema es «que toda sustancia quiere ser en acto». ${ }^{15}$ Aristóteles parte del descubrimiento de que en la presencia actual (enérgeia) se consigue la pretendida actualidad. ${ }^{16} \mathrm{Y}$ hemos visto que no es preciso recurrir a ningún mundo ideal alternativo para explicar la posibilidad de dicha actualidad en lo pensado. Basta con que la naturaleza este ordenada cíclicamente. ${ }^{17}$ Ahora bien, hay que explicar porqué se da este ordenamiento, y la clave para ello, está, como decíamos, en considerar que toda sustancia quiere ser en acto. Por otro lado, esta pretensión de actualidad no afecta sólo al mundo terrestre.

Por encima del mundo compuesto por sustancias móviles, corruptibles, integradas por los cuatro elementos, esto es, por encima del mundo terrestre, existe, según la concepción aristotélica que adopta las teorías de Eudoxio, otro mundo que es el de las sustancias celestes. Un mundo compuesto de multitud de esferas ${ }^{18}$ que giran en torno a la Tierra. Esferas etéreas compuestas por sustancias eternas, ingenerables e incorruptibles. Y aún hay una tercera región donde se da la existencia de la sustancia suprema, la actualidad del acto. Un lugar que trasciende el Universo, que no se conoce mirando el mundo físico, sino teorizando sobre el movimiento. Pues, teorizando sobre el movimiento, el teórico es conducido a la idea de una sustancia suprema causa primera y eterna del movimiento de las sustancias celestes y terrestres.

14 «Y, existiendo en cada género la distinción de lo que está en potencia y lo que está en acto (entelequia), a la actualización (energeian) de lo que está en potencia en cuanto tal la llamo movimiento (kinesis)» Metaph. XI, 9 1065b 15.

15 Metaph. XII, 7 1072b 4.

16 «En cambio, haber visto y ver al mismo tiempo es lo mismo, y pensar y haber pensado. A esto último llamo acto (energeia), y a lo anterior, movimiento» Metaph. IX, 6 1048b 33.

17 «Y resulta también esta reciprocidad: puesto que el movimiento circlar es la medida de los movimientos, tiene que ser el movimiento primero (pues todas las cosas son medidas por lo que es primero); y puesto que es primero es la medida de todos los demás» Phys, 265b 5-15.

18 49, según la corrección que Jaeger hace notar al mostrar que Aristóteles se equivoca en el clculo al decir 47 . 
Dos tipos de sustancias para dos mundos distintos, y una tercera sustancia trascendente al universo. Tres sustancias separadas entre sí cuyo hilo de unión es un pensamiento sobre el movimiento que podríamos resumir de este modo: sustancias cuyo movimiento no es circular ${ }^{19}$ (terrestres), sustancias cuyo movimiento es circular (celestes) y sustancia principio del movimiento (sustancia suprema). Tres sustancias ordenadas así de más imperfecta a más perfecta en torno a una teoría sobre el movimiento.

Si bien, en la Física el primer motor no aparece fuera del mundo, sino en la periferia de éste, formando parte de él. ${ }^{20}$ Este primer motor mueve por contacto físico y de manera semejante a como el alma mueve al cuerpo: un motor inmóvil, alma del primer cielo. Es en la Metafísica donde la sustancia inmovil se encuentra fuera del Universo.

Así, cabe destacar una diferencia decisiva entre los dos libros: mientras que el primer motor en la Fisica pertenece al universo, en la Metafísica es trascendente al Universo.

Lo primero que hay que decir en pos de su aclaración es que tanto en el mundo terrestre como en el celeste tenemos lo mismo: la pretensión del acto. En los mundos celeste y terrestre la actualidad debe ser lograda. Y la respuesta es simple, debe ser lograda porque no hay identidad. El acto sólo se da cuando se supera la diferencia. Pero identidad sólo la hay en el Dios como pensamiento que se piensa a sí mismo. ${ }^{21}$ En la actualidad del acto lo que hay es una identidad: el qué es el cómo. El pensar y lo pensado coinciden, son uno y «lo mismo». Pero en el mundo celeste y terrestre se ha instalado la diferencia.

Perdida «la identidad» que observamos en la sustancia suprema, la actualidad debe lograrse a pesar del movimiento que implica la distinción. Y esto es posible porque, aunque no se logre la unidad de lo idéntico, si se logra la unidad de lo mismo.

En el mundo celestial se consigue ónticamente «lo mismo» siempre mediante el movimiento circular que es mucho más indicado que el cíclico para conseguir el mantenimiento de lo mismo siempre. De hecho el cíclico no es sino una imitación del círculo. Si antes pusimos el ejemplo del verano, basta con hacer ver que nunca se repite el mismo verano, sino que cada verano es un verano nuevo. Claro que tampoco podemos decir que no exista la expresión de un círculo perfecto en el mundo terrestre: el movimiento elemental de agua, fuego, tierra y aire. La introducción del círculo se hace a nivel elemental, y aunque conforme nos vamos alejando del nivel elemental el círculo es más imperfecto sirve sin embargo para que sea posible ser pensado, llegando a ser en

19 Es cíclico.

20 Phys. VIII 10,267b6-10.

21 Metaph. XII, 7 1072b 20. 
acto también la sustancia terrestre. Claro que habría que señalar que conforme más alejado del círculo elemental más difícil se le hace al pensamiento pensar algo. El caso paradigmático es el de conocer al otro que es siempre, como nos enseñaran los clásicos, una novedad radical.

Podríamos concluir esta breve nota diciendo: por un lado sabemos que lo que quiere la sustancia es ser en acto (esto nos lleva al Dios de la metafísica como causa final), pero por otro lado, esto sólo puede lograrse en el mundo celeste y terrestre si se introduce el movimiento circular (el Primer Motor en contacto como causa agente) que permite la unidad entre pensar y ser como mismidad.

Esto es, por un lado observamos la pretensión del acto (finalidad) y trascendencia al Universo del Dios de la Metafísica, por otro lado, observamos circularidad en la naturaleza como «causa agente» para la posibilidad de la actualidad (presencia actual) y contacto con el Universo del Dios considerado desde esta perspectiva como Primer Motor.

El pensamiento que se piensa a sí mismo es causa final, en la medida en que toda sustancia quiere ser en acto. Pero dicha finalidad no sería posible si no se produjera el ordenamiento circular de la naturaleza (causa agente) que consigue el mantenimiento de lo mismo siempre a pesar del cambio y de esta forma hace posible la mismidad entre pensar y ser desde la que se explica la presencia actual. Que Dios mueva como causa final a las demás sustancias a ser en acto, lleva a que éstas se ordenen de tal forma que se permita el paso de lo que aún no es en acto (potencia) a lo que es en acto. Y el movimiento introducido por el primer motor para permitir este movimiento de la potencia al acto es la traslación circular. ${ }^{22}$

Expuestas así las cosas, se puede entender la relación entre el Dios en la Física y el Dios en la Metafísica, sin necesidad, por ejemplo, de interpretar que el primero sólo fue un intento primerizo que sería corregido y madurado posteriormente. ${ }^{23}$

Alejandro Rojas Jiménez. Universidad de Málaga, Facultad de Filosofía y Letras, Departamento de Filosofía

Lineas de investigación:

La heideggeriana Geviert y teorías de la verdad.

22 Cfr., Phys, 260a ss

23 Cfr. José Alberto Ross Hernández, Dios, Eternidad y movimiento en Aristóteles, Tesis doctoral, Facultad de filosofía y letras de la Universidad de Navarra, Pamplona, 2006 
Publicaciones recientes:

«Pensar-tiempo y ser: la verdad. Indicación de la relación "Pensar-Tiempo y Ser" de Parménides a Hegel y el posterior descubrimiento de la vida (de Dilthey a Heidegger)», Thémata, no 38, 2007; y Hacia la Cuadratura, SPICUM, Málaga, 2006 (ISBN: 84-9747-139-3).

Dirección postal:

C/ Océano Índico, 31. Alhaurín de la Torre (Málaga).C.P.: 29130

Dirección electrónica: rojas_a@uma.es 
